\title{
Clinical research for dose effects of ketorolac tromethamine on PCIA after hip arthroplasty
}

\author{
Hailong SONG ${ }^{1,2}$, Cong $\mathrm{LI}^{1,3}$, Changwei QU ${ }^{1}$, Yan ZHANG ${ }^{1,3 *}$ (D), Shaohua MIAO ${ }^{1,3 *}$
}

\begin{abstract}
To observe effect and safety of different doses of ketorolac tromethamine in patient controlled intravenous analgesia (PCIA) after hip arthroplasty. 60 hip arthroplasty patients injected with $0.5 \mathrm{mg} / \mathrm{kg}$ ketorolac tromethamine before anesthesia were randomly divided into group $\mathrm{A}, \mathrm{B}$ and $\mathrm{C}$ in which the patients were injected 2, 3 and $4 \mathrm{mg} / \mathrm{kg}$ ketorolac tromethamine after operation respectively. Compared with group A, MAP and HR in group B and group C were lower at T1 ( $3 \mathrm{~h}$ after operation) and T2 (6 h after operation). In group A, MAP and HR at T3 (24 h after operation) and T4 (48 h after operation) were lower than at T1. Compared with group A, NRS scores of group B and C were significantly lower during the analgesia. Compared with group $\mathrm{A}$, ramesay sedation scores in group $\mathrm{B}$ and group $\mathrm{C}$ were significantly higher at $\mathrm{T} 1$ and $\mathrm{T} 2$; Harris hip scores of group B and group C were significantly higher at T3 and T4; the total number of pushing PCA pump and dezocine dosage were significantly decreased in group B and group C. Preemptive analgesia combined with postoperative analgesia on patients after hip replacement was appropriate.
\end{abstract}

Keywords: ketorolac tromethamine; preemptive analgesia; hip replacement; dose effect.

Practical Application: Hip replacement surgery was effective with less adverse reactions in patient after hip arthroplasty, which was conducive to postoperative rehabilitation of patients.

\section{Introduction}

Evidence indicates that around $80 \%$ of patients experience postoperative pain and that $75 \%$ of patients report pain of moderate or greater severity (Chou et al., 2016). Server pain within $24 \mathrm{~h}$ after the operation in most patients belonged to acute pain. Full analgesia after hip arthroplasty is beneficial for early functional exercise, prevention of deep vein thrombosis and joint stiffness, prevention of muscle atrophy, and improvement of overall evaluation of surgical quality (Andersen et al., 2007; Dalldorf et al., 1994). After operation, trauma and other noxious stimulation, the release of prostaglandin (PG) and pain mediators from damaged tissues increases the sensitivity of effector receptors and decreases the pain threshold, leading to hyperalgesia and prolongation of duration (Almeida et al., 2008). Postoperative pain is one of the common complications after surgery. Anesthesia and analgesia during and after operation can partly inhibit stress response and reduce the incidence of stress reaction.

Nteroidal anti-inflammatory drugs (NSAIDs) play important roles in the multimodal analgesic protocol (Moizo et al., 2004; Ismail et al., 2020; Özden \& Kiliç, 2020; YuwaAmornpitak et al., 2020). Ketorolac tromethamine, otherwise known as ketorolac, is a NSAID and a pyrrolizine carboxylic acid derivative (Gurunathan et al., 2018). It is currently one of the most effective non-steroidal anti-inflammatory drugs and widely used in adult postoperative analgesia (Lee et al., 2010). It not only has a significant analgesic effect, but also has a lower incidence of adverse reactions than opioid analgesics (Isiordia-Espinoza et al., 2016). Ketorolac tromethamine attenuates the transmission of noxious stimuli to dorsal root ganglion and the response of pain nerves to endogenous pain-causing substances through inhibiting cyclooxygenase (COX) activation and reducing prostaglandin synthesis in peripheral and central systems. These effects can block peripheral sensitization, and reduce inflammation and tissue edema caused by surgery and trauma which achieve the purpose of analgesia and anti-inflammation (Carvalho et al., 2013). On the other hand, Ketorolac tromethamine can locally inhibit prostaglandin synthesis by targeting the wound, which further reduces the sensitivity of peripheral pain receptors to pain and other stimulation (Burian \& Geisslinger, 2005).

In present study, to investigate the dose-effect relationship, the effects of $0.5 \mathrm{mg} / \mathrm{kg}$ ketorolac tromethamine preemptive analgesia combined with different doses of ketorolac tromethamine postoperative analgesia on hip replacement patients were evaluated, which could provide a reference for clinical medication.

\section{Materials and methods}

\subsection{Patients' information and operation process}

The inclusion criteria were: age $\geq 18$ years, intact cognitive function, ASA score $\leq 2$, and scheduled for primary unilateral Total hip arthroplasty. Patients who were scheduled for simultaneous or staged bilateral total hip arthroplasty or for revision total hip arthroplasty were excluded. Patients with contraindications for any of the study drugs, due to allergy, regular opioid use, 
renal insufficiency, a history of cardiac disease, deep vein thrombosis, or surgery of the hip joint or spine were also excluded. Sixty patients scheduled to total hip arthroplasty with an ASA physical status of I and II were selected from October 2015 to October 2016, which consisted of 33 male patients and 27 female patients. The all patient's age was $48-65$ years old and the all patient's weight was $48-75 \mathrm{~kg}$. All 60 patients have normal blood routine and coagulation function and have no heart, lung, liver and kidney diseases. In addition, the patients with NSAIDS allergy, asthma and gastrointestinal ulcer were also excluded. The study was approved by the Ethical Committee of Taishan Medical University. Informed consent was obtained from all included patients. Before operation, electrocardiogram (ECG), mean artery pressure (MAP), heart rate (HR), pulse oxygen saturation $(\mathrm{SpO} 2)$ and respiratory rate $(\mathrm{RR})$ were monitored and $0.5 \mathrm{mg} / \mathrm{kg}$ ketorolac tromethamine was injected intravenously before anesthesia.

Patients underwent spinal anesthesia, received $500 \mathrm{~mL}$ of Ringer's solution before they were positioned upright for the induction of spinal anesthesia at the level of either $\mathrm{L} 3 / 4$ or $\mathrm{L} 2 / 3$ via a midline approach. An isobaric solution $(3.5 \mathrm{~mL})$ of bupivacaine $0.5 \%$ was administered and patients were repositioned supine. These patients breathed oxygen enriched air throughout surgery.

During the operation, MAP and HR were maintained in baseline value $+20 \%$, which were regarded as stable vital signs. Meanwhile, the operation time (from the beginning of skin incision to the end of suture) were recorded. After operation, MAP, HR, SpO2 were monitored, the anesthesia recovery time (from the end of suture skin to the recovery of normal sensation of both legs) was recorded, and oxygen was inhaled continuously by nasal catheter at the rate of $2 \mathrm{~L} / \mathrm{min}$ for 24 hours.

Compared with pre-operation, if MAP decreased by $20 \%$, $10-20 \mu \mathrm{g} / \mathrm{kg}$ dopamine was intravenous injected. If $\mathrm{HR}<50 \mathrm{bpm}$, $2-4 \mu \mathrm{g} / \mathrm{kg}$ atropine were intravenous injected. If there were nausea and vomiting, $3 \mathrm{mg}$ granisetron would be intravenous injected. If lack of analgesia, $0.05-0.1 \mathrm{mg} / \mathrm{kg}$ Dezocine would be intravenous injected.

\subsection{Analgesia protocol}

Sixty hip arthroplasty patients were intravenously injected $0.5 \mathrm{mg} / \mathrm{kg}$ ketorolac tromethamine before anesthesia. Computer-generated variable-sized block randomization plan was used to assign patients into three groups. All patients were randomly equally divided into three groups after operation: group A (injecting $2 \mathrm{mg} / \mathrm{kg}$ ketorolac tromethamine), group B (injecting $3 \mathrm{mg} / \mathrm{kg}$ ketorolac tromethamine), group C (injecting $4 \mathrm{mg} / \mathrm{kg}$ ketorolac tromethamine). Each group was combined with $1.5 \mu \mathrm{g} / \mathrm{kg}$ dexmedetomidine postoperatively. $150 \mu \mathrm{g}$ dexmedetomidine and $200 \mathrm{mg}, 300 \mathrm{mg}$ or $400 \mathrm{mg}$ ketorolac tromethamine were dilute with normal saline to $100 \mathrm{~mL}$ respective for each group. The parameters were set as $2 \mathrm{~mL}$ load dose, $2 \mathrm{~mL} / \mathrm{h}$ infusion speed and $2 \mathrm{~mL} / 30 \mathrm{~min}$ automatic dose. The patient controlled intravenous analgesia (PCIA) was used in all groups for 48 hours after operation. There was no background or loading infusion of morphine. Other analgesics such as tramadol or pethidine were used if necessary, and their consumption was added to the total quantity after conversion to the morphine equivalent dose.

\subsection{Monitoring indicators and evaluation criteria}

The MAP, HR, SpO2, NRS and Ramsay scores of T1 (3 h after operation), T2 (6 h after operation), T3 (24 h after operation), T4 (48 h after operation) among three groups were recorded. The Harris hip score (HHS), a joint specific score that is completed by both the clinician and the patient and consists of 10 items covering domains of pain, function, functional activities, deformity and hip range of motion was evaluated (Harris, 1969). The hip score (Harris) of T0 (pre-operative), T3, T4 and the total number of PCA pressing, the dosage of Dezocine and the number of adverse reactions within 48 hours after operation in all patients were counted.

In evaluation of the NRS analgesia score, 0 point represents pain, 10 points represent severe pain. For Ramesay sedation score: 1 point represents agitation, 2 points represent quiet cooperation, 3 points represent sleepiness, 4 points represent patient could be wake up in sleep state, 5 points represent patient are difficult to wake up in deep sleep state, 6 points represent anesthesia. For Harris hip score, there were 44 points for pain, 47 points for function, 5 points for range of motion and 4 points for limb deformity. Among the total score, $90-100$ point represent excellent, 80-89 point represent good, 70-79 point represent medium and 70 point below represent poor.

\subsection{Statistical analysis}

The differences between groups were evaluated using SPSS 17.0 software. The normality of distribution of continuous variables was tested by Shapiro-Wilk test. Continuous variables with normal distribution were presented as mean \pm standard error of mean (S.E.M). Means of continuous normally distributed variables were compared by One-way ANOVA. Adverse reactions were compared using Chi-square test. Least significant difference (LSD) was used to compare the mean between groups when the variance was homogeneous. Tamhane's T2 was used to test the variance when the variance was uneven. Statistically significance was set at $P<0.05$.

\section{Results}

There were no significant differences of sex ratio, age, weight, operation time and anesthesia recovery time between the three groups (Table 1) (Figure 1). In present study, there was no abnormal bleeding or analgesia interruptions patient due to severe adverse reactions.

For MAP and HR, compared with group $\mathrm{A}$, there were significant differences in both group $\mathrm{B}$ and group $\mathrm{C}$ at $\mathrm{T} 1$ and $\mathrm{T} 2$ time points $(P<0.05)$. In group $\mathrm{A}$, compared with $\mathrm{T} 1$, there were significant differences in MAP and HR at both T3 and T4 time points $(P<0.05)$. In addition, there was no respiratory depression in all three groups, and $\mathrm{SpO} 2$ was above $96 \%$ at all time points (Table 2).

For NRS analgesia score, the scores of group $\mathrm{B}$ and group $\mathrm{C}$ at each time point were significantly lower than those of group $\mathrm{A}(P<0.01)$. 
Table 1. Patients information (gender, age, body weight) comparison among group A, B and C.

\begin{tabular}{cccccc}
\hline Group & Gender (Male/Femal) & Age (year) & Body weight (kg) & Operation time (minute) & $\begin{array}{c}\text { Anesthesia Recovery } \\
\text { time (minute) }\end{array}$ \\
\hline Group A & $12 / 8$ & $53.10 \pm 3.53$ & $60.17 \pm 7.88$ & $113.25 \pm 23.06$ & $48.75 \pm 18.43$ \\
Group B & $9 / 11$ & $55.91 \pm 4.08$ & $64.53 \pm 8.62$ & $109.78 \pm 19.18$ & $50.26 \pm 15.71$ \\
Group C & $11 / 9$ & $52.14 \pm 3.55$ & $63.19 \pm 6.37$ & $120.32 \pm 22.14$ & $44.18 \pm 17.36$ \\
\hline
\end{tabular}

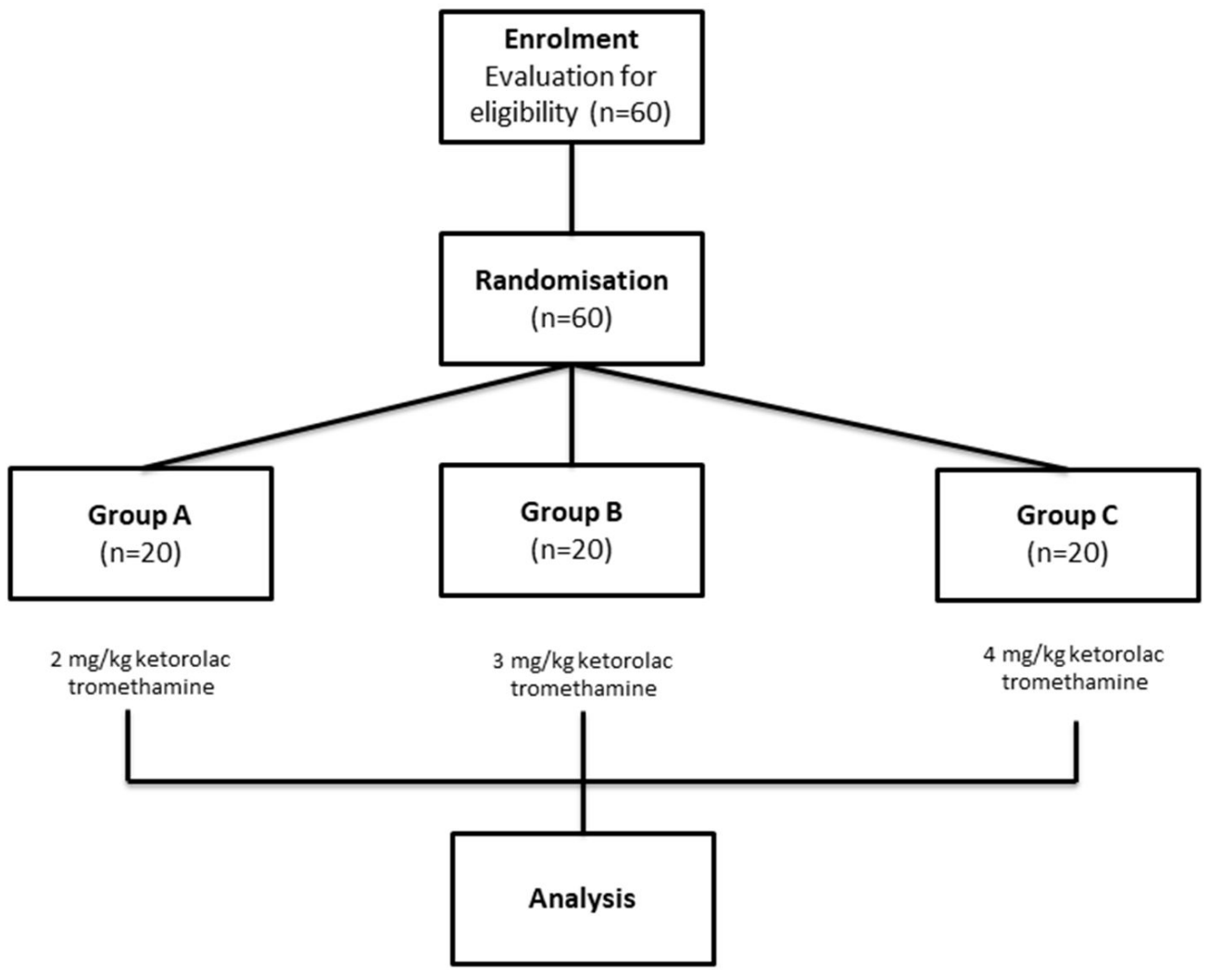

Figure 1. Different GROUP patients after hip arthroplasty with different concentrations of ketorolac tromethamine for PCIA.

There was no difference between group B and group C $(P>0.05)$. In group $\mathrm{A}$, the $\mathrm{T} 4$ score was significantly lower than that in group $\mathrm{T} 1, \mathrm{~T} 2$ and T3 $(P<0.05)$. Meanwhile, the T4 scores in group B and C were lower than those in group T1, T2 and T3 $(P<0.05)$ (Table 3).

For Ramsay sedation score comparison, the scores of group $\mathrm{B}$ and group $\mathrm{C}$ at $\mathrm{T} 1$ and $\mathrm{T} 2$ were significantly higher than those of group A $(P<0.01)$. In group A, the scores of T3 and T4 were significantly higher than that at $\mathrm{T} 1$ and $\mathrm{T} 2$ time points $(P<0.01)$. Meanwhile, in group B and $\mathrm{C}$, the scores of T3 and T4 were lower than that at $\mathrm{T} 1$ and $\mathrm{T} 2$ time points $(P<0.05)$. There was no difference in other groups $(P>0.05)$ (Table 4$)$.

For Harris hip score comparison, there was no significant difference in pre-operative (T0) scores among the three groups $(P>0.05)$. Compared with group A, Harris hip scores in group B and group $C$ were significantly higher than that at $\mathrm{T} 3$ and $\mathrm{T} 4$ time points $(P<0.01)$. Compared with T0, the Harris hip scores in T3 and T4 was significantly increased $(P<0.01)$. Similarly, there was significant difference between T4 and T3 in Harris hip score $(P<0.01)$. There was no difference between group $\mathrm{B}$ and group $\mathrm{C}(P>0.05)$ (Table 5).
For total pressing times and dosage of Dezocine in PCIA comparisons, the total number of PCIA pressing and the dosage of Dezocine in group B and C significantly decreased than that in group $\mathrm{A}(P<0.01)$ (Table 6).

For adverse reactions comparisons, 1 patient had perspiration of unknown cause in group A. There was 1 case with nausea in group B. Group C has 3 cases of nausea, 1 case of dizziness and 1 case of unexplained sweating. Compared with group $\mathrm{C}$, there was a significant difference of the total number of adverse reactions compared with group A and group B by Chi-square test $(P<0.01)$. There was no difference between group $A$ and group $B(P>0.05)$ (Table 7$)$.

\section{Discussion}

Preemptive analgesia refers to taking certain measures before noxious stimulation acting on the body, which aims to prevent sensitization of central and peripheral nerves and alleviate postoperative pain (Kelly et al., 2001). The recent concept of preventive analgesia is a pharmacological strategy based on the administration of analgesic treatment before the surgical stimulus is induced, during and after de stimulus, in order to prevent postoperative pain (Huang et al., 2018). In present study, for 
Original Article

Table 2. MAP, HR, SpO2 comparison among group A, B and C.

\begin{tabular}{cllllll}
\hline & Group & Case & \multicolumn{1}{c}{ T1 } & \multicolumn{1}{c}{ T2 } & T3 & T4 \\
\hline \multirow{3}{*}{ MAP (mmHg) } & Group A & 20 & $98.15 \pm 4.23$ & $95.37 \pm 5.26$ & $84.52 \pm 4.16 \mathbf{\Delta}$ & $85.95 \pm 3.27 \boldsymbol{\Delta}$ \\
& Group B & 20 & $81.11 \pm 3.18 \mathrm{a}$ & $80.28 \pm 4.34 \mathrm{a}$ & $82.56 \pm 5.33$ & $83.31 \pm 4.58$ \\
& Group C & 20 & $80.24 \pm 3.75 \mathrm{a}$ & $79.62 \pm 4.86 \mathrm{a}$ & $83.17 \pm 4.39$ & $82.18 \pm 4.24$ \\
& Group A & 20 & $84.29 \pm 5.13$ & $83.05 \pm 5.39$ & $74.64 \pm 5.17 \boldsymbol{\Delta}$ & $74.19 \pm 4.32 \boldsymbol{\Delta}$ \\
HR (bpm) & Group B & 20 & $72.32 \pm 4.95 \mathrm{a}$ & $73.91 \pm 3.18 \mathrm{a}$ & $72.25 \pm 4.29$ & $73.15 \pm 5.30$ \\
& Group C & 20 & $73.54 \pm 5.76 \mathrm{a}$ & $72.35 \pm 5.92 \mathrm{a}$ & $73.26 \pm 5.21$ & $74.85 \pm 4.92$ \\
& Group A & 20 & $98.18 \pm 0.39$ & $98.28 \pm 0.84$ & $98.15 \pm 0.55$ & $98.26 \pm 0.51$ \\
SpO2 & Group B & 20 & $98.27 \pm 0.54$ & $98.13 \pm 0.68$ & $98.32 \pm 0.58$ & $98.19 \pm 0.53$ \\
& Group C & 20 & $97.91 \pm 0.83$ & $97.37 \pm 0.54$ & $98.02 \pm 0.83$ & $97.97 \pm 0.66$ \\
\hline
\end{tabular}

Note: A was the control group, B and C were the experimental groups. a represent $\mathrm{P}<0.01$ in different groups; $\boldsymbol{\Delta}$ represent $\mathrm{P}<0.05$ in intra group comparison. MAP: mean arterial pressure. HR: heart rate.

Table 3. NRS score comparison in three groups.

\begin{tabular}{cllll}
\hline Group & T1 & T2 & T3 & T4 \\
\hline Group A & $3.15 \pm 0.64$ & $3.18 \pm 0.66$ & $2.72 \pm 0.37$ & $1.65 \pm 0.38 \boldsymbol{\Delta}$ \\
Group B & $0.73 \pm 0.29 \mathrm{a}$ & $0.75 \pm 0.31 \mathrm{a}$ & $0.63 \pm 0.25 \mathrm{a}$ & $0.40 \pm 0.12 \mathrm{a} \boldsymbol{\Delta}$ \\
Group C & $0.68 \pm 0.31 \mathrm{a}$ & $0.72 \pm 0.42 \mathrm{a}$ & $0.54 \pm 0.39 \mathrm{a}$ & $0.31 \pm 0.12 \mathrm{a} \boldsymbol{\Delta}$ \\
\hline
\end{tabular}

Note: $\mathrm{A}$ was the control group, $\mathrm{B}$ and $\mathrm{C}$ were the experimental groups. a represent $\mathrm{P}<0.01$ in different groups; $\boldsymbol{\Lambda}$ represent $\mathrm{P}<0.05$ in intra group comparison.

Table 4. Ramesay score comparison among group A, B and C.

\begin{tabular}{ccccc}
\hline Group & T1 & T2 & T3 & T4 \\
\hline Group A & $1.40 \pm 0.52$ & $1.42 \pm 0.51$ & $1.89 \pm 0.22 \boldsymbol{\Delta}$ & $1.88 \pm 0.21 \boldsymbol{\Delta}$ \\
Group B & $2.41 \pm 0.24 \mathrm{a}$ & $2.37 \pm 0.30 \mathrm{a}$ & $2.10 \pm 0.41 \mathbf{\Delta}$ & $2.00 \pm 0 \mathbf{\Delta}$ \\
Group C & $2.50 \pm 0.18 \mathrm{a}$ & $2.43 \pm 0.28 \mathrm{a}$ & $2.09 \pm 0.22 \boldsymbol{\Delta}$ & $2.00 \pm 0 \boldsymbol{\Delta}$ \\
\hline
\end{tabular}

Note: $\mathrm{A}$ was the control group, $\mathrm{B}$ and $\mathrm{C}$ were the experimental groups. a represent $\mathrm{P}<0.01$ in different groups; $\mathbf{\Lambda}$ represent $\mathrm{P}<0.05$ in intra group comparison.

Table 5. Harris score comparison among group A, B and C.

\begin{tabular}{cccc}
\hline Group & T0 & T3 & T4 \\
\hline Group A & $42.57 \pm 5.12$ & $51.18 \pm 2.30 \boldsymbol{\Delta}$ & $74.83 \pm 3.26 \boldsymbol{\Delta}$ \\
Group B & $43.28 \pm 3.46$ & $58.42 \pm 2.61 \mathrm{a} \boldsymbol{\Delta}$ & $81.15 \pm 3.52 \mathrm{a} \boldsymbol{\Delta}$ \\
Group C & $42.98 \pm 3.69$ & $59.35 \pm 3.01 \mathrm{a} \boldsymbol{\Delta}$ & $82.20 \pm 3.72 \mathrm{a} \boldsymbol{\Delta}$ \\
\hline
\end{tabular}

Note: $\mathrm{A}$ was the control group, $\mathrm{B}$ and $\mathrm{C}$ were the experimental groups. a represent $\mathrm{P}<0.01$ in different groups; $\boldsymbol{\Lambda}$ represent $\mathrm{P}<0.05$ in intra group comparison.

Table 6. Comparisons of total PCIA pressing times and dosage of dezocine in three groups after operation.

\begin{tabular}{ccc}
\hline Group & $\begin{array}{c}\text { Total times of PCIA } \\
\text { compression (times) }\end{array}$ & Dosage of dezocine $(\mathrm{mg})$ \\
\hline Group A & $28.26 \pm 5.18$ & $11.22 \pm 1.72$ \\
Group B & $8.62 \pm 2.76 \mathrm{a}$ & $3.35 \pm 1.85 \mathrm{a}$ \\
Group C & $7.15 \pm 3.24 \mathrm{a}$ & $3.51 \pm 1.27 \mathrm{a}$ \\
\hline
\end{tabular}

Note: A was the control group, $\mathrm{B}$ and $\mathrm{C}$ were the experimental groups. a represent $\mathrm{P}<0.01$ in different groups.

Table 7. Statistics and comparison of adverse reactions in three groups.

\begin{tabular}{cccccc}
\hline Group & Nausea & Vomit & Dizzy & Sweat & $\begin{array}{c}\text { Number } \\
\text { of cases }\end{array}$ \\
\hline Group A & 0 & 0 & 0 & 1 & $1 \mathrm{c}$ \\
Group B & 1 & 0 & 0 & 0 & $1 \mathrm{c}$ \\
Group C & 3 & 0 & 1 & 1 & 5 \\
\hline
\end{tabular}

Note: A was the control group, B and C were the experimental groups. C represent $\mathrm{P}<0.01$ in different groups. preemptive analgesia, all three groups were given $0.5 \mathrm{mg} / \mathrm{kg}$ ketorolac tromethamine before anesthesia. Furthermore, considered the side effects of ketorolac tromethamine (Campobasso et al., 2008), patients with NSAIDS allergy, gastrointestinal ulcer and asthma were excluded. Preoperative examination showed there were no heart, lung, liver or kidney diseases and all patients had normal blood routine and coagulation function. On the one hand, platelet dysfunction, kidney damage and bleeding after operation may be caused by ketorolac tromethamine therapy. However, it was believed that low dose and short-term application of ketorolac tromethamine would not increase the risk of bleeding after operation (Vadivelu et al., 2015). In our study, there was no abnormal bleeding and no analgesia interruptions patients due to severe adverse reactions.

The NRS analgesic score of group A was significantly higher than that of group B and group C in T1, T2, T3 and T4. For Ramesay sedation scores, the score in group A was significantly lower than those in group B and C at T1 (6 hours after operation) and T2 (6 hours after operation) time points. The Harris hip score in group A was significantly lower than that in group B and C at T3 (24 hours after operation) and T4 (48 hours after operation) time points. Meanwhile, the number of PCA pressing and the dosage of Dezocine after operation in group A were higher than those in group B and C at T3 ( 24 hours after operation) and T4 (48 hours after operation) time points. These results were related to the inadequate effective dose of $2 \mathrm{mg} / \mathrm{kg}$ ketorolac tromethamine, which resulted in 
poor analgesia, inadequate cooperation in quiet state and affecting hip joint activity.

On the other hand, with the increase of ketorolac tromethamine dosage, there was no significant difference of analgesia and sedation scores and PCIA pressing times between group B and group $\mathrm{C}$, but the incidence of adverse reactions in group $\mathrm{C}$ was significantly higher than that in group $\mathrm{A}$ and group $B$. These results suggest that $4 \mathrm{mg} / \mathrm{kg}$ ketorolac tromethamine does not enhance the analgesic effect of patients, but increase the number of adverse reactions. This may be due to the increase of ketorolac tromethamine dose aggravating the inhibition of COX-2 in vivo and lead to the occurrence of cardiovascular and cerebrovascular adverse reactions (Acharya \& Dunning, 2010).

There were also some limitations in this study. First, the sample size is small. Second. this was only preliminary study, therefore, further study with strict design was needed.

\section{Conclusion}

In conclusion, for hip replacement surgery, $0.5 \mathrm{mg} / \mathrm{kg}$ ketorolac tromethamine preemptive analgesia combined with $3 \mathrm{mg} / \mathrm{kg}$ ketorolac tromethamine post-operative analgesia was effective with less adverse reactions in patient after hip arthroplasty, which was conducive to postoperative rehabilitation of patients.

\section{References}

Acharya, M., \& Dunning, J. (2010). Does the use of non-steroidal antiinflammatory drugs after cardiac surgery increase the risk of renal failure? Interactive Cardiovascular and Thoracic Surgery, 11(4), 461467. http://dx.doi.org/10.1510/icvts.2010.239053. PMid:20639308.

Almeida, D. R. P., Johnson, D., Hollands, H., Smallman, D., Baxter, S., Eng, K. T., Kratky, V., ten Hove, M. W., Sharma, S., \& El-Defrawy, S. (2008). Effect of prophylactic nonsteroidal antiinflammatory drugs on cystoid macular edema assessed using optical coherence tomography quantification of total macular volume after cataract surgery. Journal of Cataract and Refractive Surgery, 34(1), 64-69. http://dx.doi.org/10.1016/j.jcrs.2007.08.034. PMid:18165083.

Andersen, L. J., Poulsen, T., Krogh, B., \& Nielsen, T. (2007). Postoperative analgesia in total hip arthroplasty: a randomized double-blinded, placebo-controlled study on peroperative and postoperative ropivacaine, ketorolac, and adrenaline wound infiltration. Acta Orthopaedica, 78(2), 187-192. http://dx.doi.org/10.1080/17453670710013663. PMid:17464605.

Burian, M., \& Geisslinger, G. (2005). COX-dependent mechanisms involved in the antinociceptive action of NSAIDs at central and peripheral sites. Pharmacology \& Therapeutics, 107(2), 139-154. http://dx.doi.org/10.1016/j.pharmthera.2005.02.004. PMid:15993252.

Campobasso, C. P., Procacci, R., \& Caligara, M. (2008). Fatal adverse reaction to ketorolac tromethamine in asthmatic patient. The American Journal of Forensic Medicine and Pathology, 29(4), 358-363. http://dx.doi.org/10.1097/PAF.0b013e318185a00a. PMid:19259027.

Carvalho, B., Lemmens, H. J., Ting, V., \& Angst, M. S. (2013). Postoperative subcutaneous instillation of low-dose ketorolac but not hydromorphone reduces wound exudate concentrations of interleukin- 6 and interleukin-10 and improves analgesia following cesarean delivery. The Journal of Pain, 14(1), 48-56. http://dx.doi. org/10.1016/j.jpain.2012.10.002. PMid:23218935.

Chou, R., Gordon, D. B., de Leon-Casasola, O. A., Rosenberg, J. M., Bickler, S., Brennan, T., Carter, T., Cassidy, C. L., Chittenden, E. H., Degenhardt, E., Griffith, S., Manworren, R., McCarberg, B., Montgomery, R., Murphy, J., Perkal, M. F., Suresh, S., Sluka, K.,
Strassels, S., Thirlby, R., Viscusi, E., Walco, G. A., Warner, L., Weisman, S. J., \& Wu, C. L. (2016). Management of postoperative pain: a clinical practice guideline from the American Pain Society, the American Society of Regional Anesthesia and Pain Medicine, and the American Society of Anesthesiologists' Committee on Regional Anesthesia, Executive Committee, and Administrative Council. The Journal of Pain, 17(2), 131-157. http://dx.doi.org/10.1016/j. jpain.2015.12.008. PMid:26827847.

Dalldorf, P. G., Perkins, F. M., Totterman, S., \& Pellegrini, V. D. Jr. (1994). Deep venous thrombosis following total hip arthroplasty: effects of prolonged postoperative epidural anesthesia. The Journal of Arthroplasty, 9(6), 611-616. http://dx.doi.org/10.1016/08835403(94)90114-7. PMid:7699373.

Gurunathan, U., Parker, S. L., Maguire, R., Ramdath, D., Bijoor, M., Wallis, S. C., \& Roberts, J. A. (2018). Population pharmacokinetics of periarticular ketorolac in adult patients undergoing total hip or total knee replacement surgery. Anesthesia and Analgesia, 129(3), 701-708. PMid:31425209.

Harris, W. H. (1969). Traumatic arthritis of the hip after dislocation and acetabular fractures: treatment by mold arthroplasty: An end-result study using a new method of result evaluation. The Journal of Bone and Joint Surgery. American Volume, 51(4), 737-755. http://dx.doi.org/10.2106/00004623-196951040-00012. PMid:5783851.

Huang, C. C., Sun, W. Z., \& Wong, C. S. (2018). Prevention of chronic postsurgical pain: the effect of preventive and multimodal analgesia. Asian Journal of Anesthesiology, 56(3), 74-82. PMid:30583329.

Isiordia-Espinoza, M. A., Pozos-Guillen, A., Martinez-Rider, R., \& PerezUrizar, J. (2016). Comparison of the analgesic efficacy of oral ketorolac versus intramuscular tramadol after third molar surgery: a parallel, double-blind, randomized, placebo-controlled clinical trial. Medicina Oral, Patologia Oral y Cirugia Bucal, 21(5), e637-e643. http://dx.doi. org/10.4317/medoral.21077. PMid:27475688.

Ismail, G. A., Gheda, S. F., Abo-Shady, A. M., \& Abdel-Karim, O. H. (2020). In vitro potential activity of some seaweeds as antioxidants and inhibitors of diabetic enzymes. Food Science and Technology, 40(3), 681-691. http://dx.doi.org/10.1590/fst.15619.

Kelly, D. J., Ahmad, M., \& Brull, S. J. (2001). Preemptive analgesia I: physiological pathways and pharmacological modalities. Canadian Journal of Anaesthesia, 48(10), 1000-1010. http://dx.doi.org/10.1007/ BF03016591. PMid:11698320.

Lee, S. Y., Lee, W. H., Lee, E. H., Han, K. C., \& Ko, Y. K. (2010). The effects of paracetamol, ketorolac, and paracetamol plus morphine on pain control after thyroidectomy. The Korean Journal of Pain, 23(2), 124-130. http://dx.doi.org/10.3344/kjp.2010.23.2.124. PMid:20556214.

Moizo, E., Berti, M., Marchetti, C., Deni, F., Albertin, A., Muzzolon, F., \& Antonino, A. (2004). Acute Pain Service and multimodal therapy for postsurgical pain control: evaluation of protocol efficacy. Minerva Anestesiologica, 70(11), 779-787. PMid:15699914.

Özden, S., \& Kiliç, F. (2020). Performance evaluation of GSA, SOS, ABC and ANN algorithms on linear and quadratic modelling of eggplant drying kinetic. Food Science and Technology, 40(3), 635-643. http:// dx.doi.org/10.1590/fst.12719.

Vadivelu, N., Gowda, A. M., Urman, R. D., Jolly, S., Kodumudi, V., Maria, M., Taylor, R. Jr., \& Pergolizzi, J. V. Jr. (2015). Ketorolac tromethamine - routes and clinical implications. Pain Practice, 15(2), 175-193. http://dx.doi.org/10.1111/papr.12198. PMid:24738596.

Yuwa-Amornpitak, T., Butkhup, L., \& Yeunyaw, P.-N. (2020). Amino acids and antioxidant activities of extracts from wild edible mushrooms from a community forest in the Nasrinual District, Maha Sarakham, Thailand. Food Science and Technology, 40(3), 712-720. http://dx.doi. org/10.1590/fst.18519. 